\title{
Factors Influencing Employee Satisfaction in Education Sector at Sana'a, Yemen
}

\author{
Dr. Mohammed Abdulrazzaq Alaghbari * \\ College of Administrative Sciences, Applied Science University, PO box 5055, East Al-Ekir, Kingdom of \\ Bahrain \\ Dr. Baligh Ali Hasan Beshr \\ College of Administrative \& Financial Sciences, Gulf University, PO box 26489, Kingdom of Bahrain
}

\begin{abstract}
The employee's satisfaction has been revealed to be important to the success of the company's goals particularly in constructing competitive benefit above other establishments. This research aims to investigate on the impact of human resource practices to employee satisfaction in education sector in Sana'a Yemen with consideration of the current status of the country, and explore the factors that affect satisfaction. Centred on prior studies, the other investigators established that there is a direct connection among those variables (human resource practices) and satisfaction of employees. The prime facts of this study was gathered by assigning questionnaires to corresponding teachers in 8 public high school in Sana'a Yemen. The reliability test was fulfilled as Cronbach's Alpha, which displayed rational reliability grades with more than 0.9 alphas. Pearson Correlation Coefficient is used to examine the strength of answers from the questionnaires that were gathered. Largely, several variables obtained coefficient ranging from \pm 0.7 to \pm 0.85 which specified modest to high strength of relationship. Finally, the results in this research is demonstrate the issues which are the human resource practices, having important connection with employee satisfaction in education industry. These independent variables action a vital role in touching employee satisfaction, and should be more anxious by the government. Furthermore, this investigation also provided researcher practitioner valued in depth for upcoming studies.

Keywords: Employee's satisfaction, Human resource practices, Staffing, Training, Compensation and reword.

DOI: $10.7176 /$ EJBM/11-9-05

Publication date:March $31^{\text {st }} 2019$

\section{Introduction}

The purpose of this study is to test the relationship between human resource practices with its dimensions (Staffing, Training and Compensation), and employee's satisfaction in education industry in Sana'a - Yemen. Background of study, problem statement, objectives of research and research questions, study hypotheses, significance of research, and conclusion are incorporated in this research paper.
\end{abstract}

\subsection{Study Background}

Teacher turnover is a global challenge and, by its very nature, is an extremely complex phenomenon. It is frequently positioned as either a problem for the poor quality of schooling and teacher morale due to the current status of Yemen or human resources management practices and planning.

According to Ministry of Education released report, 2016, big number of high school teachers have resigned or left their job due to the stop of receiving the monthly salary; the current situation of Yemen has increased the suffering of the people of Yemen in general and in the education sector in particular. The UN Office for the Coordination of Humanitarian Affairs (OCHA) has reported that more than 170 schools and 70 health facilities have been fully or substantially compromised (Giulio, 2018)

Employee Satisfaction denotes to the period of staff to be engaged in an association whereas turnover intention was meant by the quantity of workers requires parting the company.

\subsection{Problem Statement}

The lack of high school teachers satisfaction is not the latest matter plus it has fetching as a serious topic globally. Once there is no efficient human resource practices and no equality in the system of distributing the compensations and bonuses among employees for sure will cause a decrease on the employee's satisfaction and effecting the commitment of the employees (Karar, 2013). In numerous emergent nations, the deficiency is poorer since a lot of skilled teachers need to leave their own nations and plot to work in advanced nations for greater incomes and rewards. Appropriate staffing and recruitment in adding to established employees will assure the excellence of education sectors.

The contest of satisfactions staffs have puzzled many administrators and trade proprietors. A lot of groups are alarming about their competence to sustain those main personnel as they are in excessive demand and hard to be substituted (Brown, Fraser, Wong, Muise, \& Cummings, 2013). Acquaintance employees are less probable to 
stay faithful to one institute with the new occupation model (Kumar \& Santhosh, 2014). The continuous turnover of workforces will carry inferences to the residual workers as there will be disruption and enlarged workload to them (Neog \& Barua, 2015). Moreover, as dissatisfaction persists, their organizational commitments fades away and they have the intention of leaving work, which over time may turn into functional turnover (Bakotica, 2016). Letdown in retaining key workers will grow directorial concerns like training instance and missing awareness. Employee turnover costs are too much where it has gravely affect the organization's foundation (Appiah, Kontar, \&Asamoah, 2013). Consequently, employee satisfaction is dynamic as it carries inferences for organizational effectiveness in a progressively worldwide background (Idris, 2014).

\subsection{Research Question}

The following is the research question for this research:

Is there a relationship between Human Resources Practices and employees' satisfaction?

The following are the sub research questions:

1. Is there a relationship between staffing and employee's satisfaction?

2. Is there a relationship between training and employees' satisfaction?

3. Is there a relationship between the compensation and employees' satisfaction?

\subsection{Hypothesis of Study}

H1: There is a relationship between staffing and employee's satisfaction.

$H 2$ : There is a relationship between training and employee's satisfaction.

H3: There is a relationship between the compensation and employee's satisfaction.

\section{Literature Review}

HRM is the prominent success factor of an organization. The five functional areas are associated with effective HRM:

staffing, human resource development, compensation and benefits, safety and health, and employee and labor relations

(Mondy and Noe 2005)

HRM is the prominent success factor of an organization. The five functional areas are associated with effective HRM:

staffing, human resource development, compensation and benefits, safety and health, and employee and labor relations

(Mondy and Noe 2005)

Human Resource Management (HRM) is the prominent success factor of an organization. There are five functional areas associated with effective HRM which are staffing, human resource development, compensation and benefits, safety and health, and employee and labor relations (Mondy and Noe 2005). These five areas function around providing sufficient space to achieving employee's retention through satisfaction.

Most of the discussion evolves around how achieving employees' satisfaction is the key to retain them. Employees' satisfaction comes in line with the availability of conducive environment such as facilities which are attractive, management support and employees' opportunities for growth. This in turn helps in retaining competent employees. Fundamentally, it functions to raise the morale of employees in the organization with increased job satisfaction. Further emphasis on retention urges organizations to develop and implement retention strategies in order to increase the satisfaction of employees (Armstrong, 2009). This is viewed to reflect the preferment of sustaining of employees in a single corporation or group for a maximum period (Hong, Hao, Kumar, Ramendran, \& Kadiresan, 2012). Administrations have to put various attempts to boost workers to be enthusiastic, dedicated and engrained in the group or establishment (Kyi, 2011). Several studies have concluded that retaining the right individuals, with the right set of attitudes, within the organization is more challenging then recruiting for new talents. The employing of new brilliant personnel might be one of the utmost significant topics for the sustainability of an institute; though, holding the appreciated personnel could be a far better fund saving and more operational process for the group (Rappaport, Bancroft, \& Okum, 2003). The 'war of talent' is decisive for business.

Silbert (2005) argues that reward systems are among the best strategy used by most of the organization to retain its employees and is essential to employees because it brings about positive perception with the organization. Due to the increasing diversity of the workforce and competition in the business environment more creative approaches must be adopted by employers to provide the right rewards to the right people (Staw,1980). Generally rewards can be used to motivate employees in order to retain them such as increased pay, promotion, appreciation, positive recognition for higher performers, bonuses, free trips, opportunity to use one's ability, and a sense of challenge and achievement (Mullins,2005: Armstrong, 2009). Every employee needs to be recognized, for doing a good job; the performance recognition makes individuals feel better about themselves and their organization, therefore works with the organisation for an extended period (Ishigaki, 2004). 
According to Horwitz (2008), skills shortages are a threat to economic growth. therfore, retention strategis goes long way in a global market that is confronted with a shortage of skilled workers. It is therefore essential for business, government public and private sector leaders to address this critical component of employee retention for competitiveness and service delivery. On another line of argument, Moseley et al. (2008) argue that employee retention is essential to organizations as increased turnover creates instability and puts additional workload and stress on remaining staff, increasing job dissatisfaction and therefore potentiating the turnover cycle.

Therefore, one of the key factors that fascilitates employees retentions is the avialbility of professional development that are in the form of job training and ongoing development opportunities. This results in active commitment beause employees will strongly identify with the organization if their personal goals are being met by the organisation (Coetzee and Schreuder 2013). This active commitment often prompts employees to stay with the organisation. Therefore it is imperative for any organization to provide its employees with adequate training and keep track of their level of job satisfaction.

Human Resources Practices:

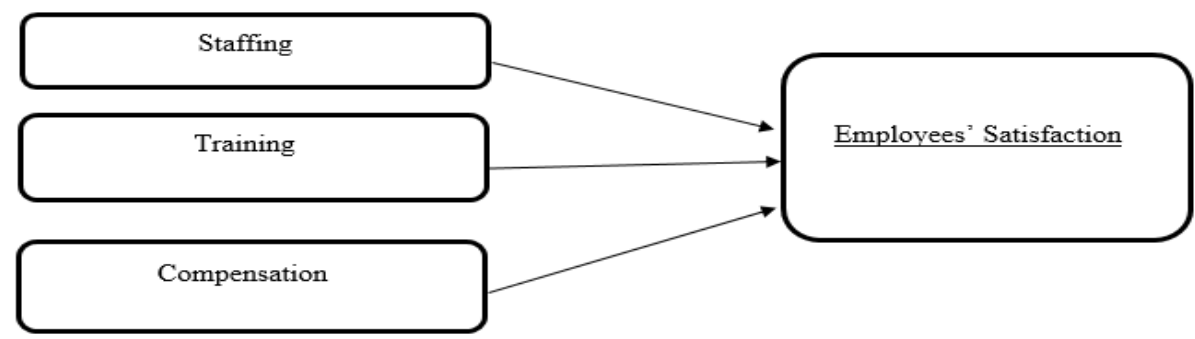

Independent Variables

Dependent Variables

\section{Research Methodology}

For the current work, quantitative examination is being applied and questionnaires are circulated as the tool to gather facts for the investigation. Mathematical tools and analysis evaluate the figures gathered through circulation of questionnaires. Quantitative method is utilized to satisfy the big sum of respondents from a widespread populace. Arithmetical and statistical tools (Venkatesh, Brown, \& Bala, 2013) confirm quantitative experiments. Primary data is unique facts gathered for a precise investigation aim (Hox \& Boeije, 2005). Questionnaire is proposed to use as primary figures in this study which provide a group of framed queries for the respondents to reply. Questionnaires will also offer more precise and trustworthy data for member to carry out the work.

To manner the real investigation, we have 8 high school in Sana'a for target respondents. We tripped our aimed respondents to collect 30 responses of every School and given matrons with envelopes and stamps to place back the finished questionnaires to us. After a week, we productively composed back the questionnaires with reply. Capable to gather back 211 questionnaires, the response rate is $87.91 \%$.

After collecting the data, it was concluded and scrutinized with the means of a software acknowledged as 'Statistical Analysis System Enterprise Guide (SAS).

\section{RESEARCH RESULTS}

This part organizes descriptive and inferential scrutiny; the outcome of questionnaire were being assessed. The outcome been analyzed and separated into various portions such as central tendencies measurement, reliability check, Pearson Correlation Analysis

\subsection{Central Tendencies Measurement of Constructs}

Central tendencies are used to display the value of mean and standard deviation of all the questions in the questionnaires. SAS system has been used to find out these values.

Table 1: Summary of Central Tendencies Measurement

\begin{tabular}{|l|l|l|l|}
\hline Variables & Dimensions & Mean & Standard Deviation \\
\hline \multirow{5}{*}{ Independent Variables } & Human Resources Practices & & \\
\cline { 2 - 4 } & Staffing & 3.78 & 1.026 \\
\cline { 2 - 4 } & Training & 3.99 & 1.020 \\
\cline { 2 - 4 } & Compensation and Rewards & 4.26 & 0.725 \\
\hline Dependent Variable & Employees' Satisfaction & 4.54 & 0.587 \\
\hline
\end{tabular}

As stated in the table, compensation and reward training have the highest rank of mean, which is 4.26 while staffing has the lowest rank of mean (3.78). The lowest standard deviation among the independent variables is belongs to Compensation and Rewards which is 0.725 while staffing has the highest standard deviation which is 
1.026. In the other hands, the dependent variable, Employees' Satisfaction received very high rank of mean which is 4.54 .

\subsection{Reliability Test}

Reliability test had been used to test on all 211 sets of questionnaires distributed in actual study to determine the reliability of the questions. The table below shows the result of the reliability test.

Table 2: Result of the Reliability Test

\begin{tabular}{|l|l|l|}
\hline Variables & Dimensions & Cronbach's Alpha \\
\hline Independent Variables & Human Resources Practices & 0.907 \\
\cline { 2 - 3 } & Staffing & 0.786 \\
\cline { 2 - 3 } & Training & 0.826 \\
\cline { 2 - 3 } & Compensation and Rewards & 0.861 \\
\hline Dependent Variable & Employees' Satisfaction & 0.898 \\
\hline
\end{tabular}

The Cronbach's Alpha value of employees' satisfaction were 0.898 which indicated that it has a very good reliability. However, the Cronbach's Alpha value of staffing is 0.786 which is stays in the very good reliability The Cronbach Alpha's value of training is 0.826 which stay in the range of good reliability. The Cronbach's Alpha value of compensation and rewards is 0.861 is indicated a good reliability. The reliability result of the human resources practices as one sum is 0.907 which is indicated very good reliability.

\subsection{Pearson's Correlation Coefficient}

A Pearson correlation coefficient will indicate the direction, strength and significance of the bivariate relationships among all the variables.

\subsubsection{Staffing and Employees' Satisfaction}

The table below illustrating the relationship between staffing and employees' satisfaction as positive due to the positive value for correlation coefficient. The staffing has a 0.785 correlation with the employees' satisfaction. Thus, when human resource practices are high, employees' satisfaction is high. The value of 0785 falls within the coefficient range of \pm 0.71 to \pm 0.90 . Therefore, the correlation is high. The relationship is significant because the p-value $<0.0001$ is less than alpha value 0.05 .

Table 3: Correlations between Staffing (HS) and Employees' Satisfaction (ES)

\begin{tabular}{|l|l|l|}
\hline & & ES \\
\hline HS & Pearson Correlation & 0.785 \\
& p-Value & $<0.001$ \\
& N & 211 \\
\hline & Pearson Correlation & 1 \\
& p-Value & \\
& N & 211 \\
\hline
\end{tabular}

\subsubsection{Training and Employees' Satisfaction}

The table below illustrating the relationship between training and employees' satisfaction is positive due to the positive value for correlation coefficient. Thus, when training is high, employees' satisfaction is high. The value of 0.843 falls within the coefficient range of \pm 0.71 to \pm 0.90 . Therefore, the relationship is high. The relationship is significant because the $\mathrm{p}$-value $<0.0001$ is less than alpha value 0.05 .

Table 6: Correlations between Training (HT) and Employees' Satis
\begin{tabular}{|l|l|l|}
\hline HT & Pearson Correlation & ES \\
& p-Value & 0.843 \\
& $\mathrm{~N}$ & $<0.001$ \\
\hline & Pearson Correlation & 211 \\
& p-Value & 1 \\
& $\mathrm{~N}$ & 211 \\
\hline
\end{tabular}

\subsubsection{Compensation and rewards and Employee Retention}

The table below illustrating the relationship between compensation and rewards and employees' satisfaction is positive due to the positive value for correlation coefficient. Thus, when compensations and rewards is high, employees' satisfaction is high. The value of 0.889 falls within the coefficient range of \pm 0.71 to \pm 0.90 . Therefore, the relationship is high. The relationship is significant because the p-value $<0.0001$ is less than alpha value 0.05 . 


Table 7: Correlations between HC and Employees' Satisfaction (ES)
\begin{tabular}{|l|l|l|}
\hline & & ES \\
\hline HC & Pearson Correlation & 0.889 \\
& p-Value & $<0.001$ \\
& N & 211 \\
\hline & Pearson Correlation & 1 \\
& p-Value & \\
& N & 211 \\
\hline
\end{tabular}

\section{Discussions, Conclusions and Recommendations \\ 5.1 Discussions}

The outcome of the study reported that there is a strong correlation between human resource practices and employee satisfaction in the education sector. This can be seen in several dimensions. It has pointed out that when the organizational human resource practices are more; the employee satisfaction in the education sector is also more. Additionally, HRM practices had a significant impact on employee attitudes such as job satisfaction, according to Edgar and Greare (2005).

Moreover, the result of the research shows a positive outcome for Pearson correlation which elaborates a definite connection between the HR practices and employee satisfaction. Briefly, in companies where poor staffing process and poor training programs occur, poorer employee satisfaction will be resulted. Training and development have a significant positive impact on employees' job satisfaction. In line with an examination from Jalal Hanaysha (2015), an employee who gets training has a significant positive effect on job satisfaction, and also the result confirms the finding of (Garcia 2005).

This study concludes that effective human resource practices are the main factors influencing employee satisfaction. The rewards and compensations are portions of the solid indicator that affect staff satisfaction. Specifically, in education sectors, a stable reward and compensations bundle results in greater job satisfaction and teacher retention rate.

\subsection{Conclusions}

In short we can say, the results in this research is demonstrate the issues which are human resource practices (Staffing, Training, and compensations and reward), having important connection with employees' satisfaction in education industry.

These all independent variables action a vital role in touching employees' satisfaction, and should be more anxious by schools principals and government. Furthermore, this investigation also provided researcher and education practitioner valued in depth for upcoming studies. Coming and current studies need put care on other factors distressing employees' Satisfaction. So, next coming generation can get correct knowledge and information.

\subsection{Recommendations}

As in this fast moving environment, employee's Satisfaction is one of the major elements for an organization to encourage its sustainability and survivorship. The research is recommended that more training need to be provided to the teachers as it shows how important for teachers to improve their skills in teaching and assessments. The research also recommended that the human resources authority in schools need to ensure there is no salary release lateness. Finally Specific time should be given to teachers to answer the question in the questionnaires. The lengthen time restraints would enable the teachers to review the questions more and accurate answers could be get.

It is suggested to large the sample size as well as the areas of analyses by including other type of schools and from different cities not only Sana'a. Big sample size amplifies the chance of worth where it is a more reliable indicator to display population means (Lin, Henry C. Lucas, \& Shmueli, 2013). Big size sample also prevents the effect of extreme observations.

There is a small difficulty of using quantitative methodology in directing our research. Therefore, it is suggested to increase the research by mixing both qualitative and quantitative methods in a research (Castellan, 2010). On the other hand from scalable measure found through quantitative approaches, qualitative measures are obtainable to advance the results.

\section{References}

Appiah, F., Kontar, E., \&Asamoah, D. (2013). Effect of Human Management Practices on Employee Retention :

Perspectives from the Mining Industry in Ghana. International Research Journal of Arts and Social Sciences, 2(2), 31-48.

Armstrong, M. (2009). Armstrong's handbook of human resource management practice. London: Kogan Page. Bakotica, D. (2016) Relationship between job satisfactions and organizational performance. Economic Research, 
29(1), 118-130

Bashir, S; \&Ramay, MI (2008). Determinants of Organizational Commitment A Study of Information Technology Professionals in Pakistan Mohammad.

Brown, P., Fraser, K., Wong, C. A., Muise, M., \& Cummings, G. (2013). Factors Influencing Intentions to Stay and Retention of Nurse Managers : A Systematic Review. Journal of Nursing Management, 21, 459-472.

Cartledge S. Factors influencing the turnover of intensive care nurses. Intensive Crit Care Nurs. 2001; 17:348355.

Castellan, C. M. (2010). Quantitative and Qualitative Research: A View for Clarity. International Journal of Education, 2(2), 1-14.

Coetzee M, Schreuder D 2013. Personnel Psychology: An Applied Perspective. South Africa: Oxford University Press

Ching-Chow Yang, Jiun-Yan Shiau, Hui-Hua Wang, (2006) "The development of an employee satisfaction model for higher education", The TQM Magazine, Vol. 18 Issue: 5, pp.484-500,

Edgar, F. and Greare, A. (2005). HRM practice and employee attitudes: Different measures-different results Personnel Review, Vol.34, No.5, pp. 534-549.

Garcia, M. (2005). Training and business performance: The Spanish case, International Journal of Human Resource Management, Vol.16, pp.1691-1710.

Giulio Coppi, (2018). The Humanitarian Crisis in Yemen: Beyond the Man-Made Disaster. International Peace Institute.

Hox, Joop J., and Hennie R. Boeije. "Data collection, primary vs. secondary." Encyclopedia of social measurement 1 (2005): 593-599.

Hsu, C., Chang, C., Huang, H., \& Chiang, C. (2011). The relationshio among social capital, organizational commitment and customer-oriented prosocial behavior of hospital nurses. Journal of Clinical Nursing, 20: 1383-1392.

Hui, L., Qun, W., \& Lin, C. (2014) Intermediary Role of Job Burnout between Individual Organization Matching and Turnover Intention Based on Regression Analysis.

Idris, A. (2014). Flexible Working as an Employee Retention Strategy in Developing Countries. Journal of Management Research, 14(2), 71-86.

Ishigaki, D. (2004) Effective Management through Measurement. Available at: http://www.ibm.com/developerworks/rational/library/4786.html

Hanaysha, J., Tahir, P. Examining the Effects of Employee Empowerment, Teamwork, and Employee Training on Job Satisfaction, Procedia - Social and Behavioral Sciences, Volume 219, 31 May 2016, Pages 272-282

Horwitz F 2008. Retention strategies critical in a global market skills shortage. Resource Management Journal, 13(4): 23-44.

Koonar, K. (2008). Nursing Assistant-An Intergal Part of the System. Available at: http://rnnurseschools.com/tag/assistant/

Karar, H. (2013). The impact of the internal work environment on the degree of job satisfaction, Nuluien University. Sudan

Kumar, G. G., \&Santhosh, C. (2014). Factor Analysis Approach to Explore Dimensions of Employee Retention in BPO Industry in Kerala. Journal of Social Welfare and Management, 69-78.

Kyi, K. M. (2011) Factor affecting employee retention in non-profit organizations :Dissertation. Adventist International institute of Advance studies. Philippine.

Lin, M., Henry C. Lucas, J., \& Shmueli, G. (2013). Too Big to Fail: Large Samples and the p-Value Problem. Information Systems Research, 1-11.

Moseley A, Jeffers L, Patterson J 2008. The retention of the older nursing workforce: A literature review exploring factors that influence the retention and turnover of older nurses. Contemporary Nurse. Australian Nursing Profession, 30(1): 46-56.

Mondy, R. W., and Noe, R. M.(2005). Human Resource Management, 9th Ed, Pearson Education, Inc.

Mullins, J.L. (2005).Management and organizational behavior, pearson education limited, Edinburgh, England.

Narang, U. (2013). HRM Practices - Its Impact on Employee Retention. International Journal of Multidisciplinary Research in Social \& Management Sciences, 1(4), 48-51.

Neog, B. B., \& Barua, M. (2015). Factors Affecting Employee's Retention in Automobile Service Workshops of Assam : An Empirical Study. The SIJ Transactions on Industrial, Finance \& Business Management (IFBM), 3(1), 9-18.

Ng, E. C., Lam , Z. H., Kumar, R., Ramendran, C., \& Kadiresan, V. (2012). An Effectiveness of Human Resource Management Practices on Employee Retention in Institute of Higher Learning : - A Regression Analysis. International Journal of Business Research and Management (IJBRM), 3(2), 60-79.

Rappaport, A., Bancroft, E., \& Okum, L. (2003). The aging workforce raises new talent management issues for employers. Journal of Organizational Excellence, 23, 55-66. 
Silbert, L.T. (2005). The effect of Tangible Rewards on Perceived Organizational Support. Management Sciences. Staw, B.M. (1980). The consequences of turnover. Journal of Organizational Behaviour, 1, 253- 273.

Venkatesh, V., Brown, S. A., \& Bala, H. (2013). Bridging The Qualitative-Quantitative Divide : Guidelines for Conducting Mixed Methods Research in Information Systems. MIS Quarterly, 37(1), 21-54.

Yeun, E. J., Bang, H. Y., \& Jeon, M. S. (2013). Supervisor's Support, Emotional Exhaustion, Personal Accomplishment and Life Satisfaction among Hospital Nurses. International Journal of Digital Content Technology and its Applications, 7(12), 222. 